\title{
A permanência no ensino superior e as estratégias institucionais de enfrentamento da evasão ${ }^{1}$
}

\author{
The permanence in higher education and the institutional \\ strategies of avoidance truancy
}

\author{
La permanencia en la educación superior y las estrategias \\ institucionales de la evitación de la evasión
}

\section{Silvio Luiz da Costa ${ }^{2}$ Sonia Maria Barbosa Dias ${ }^{3}$}

\section{Resumo}

O artigo reflete o papel de políticas institucionais voltadas para a garantia da permanência e desempenho escolar no contexto da ampliação do acesso ao ensino superior no Brasil. Considera a questão da evasão e as dificuldades enfrentadas, sobretudo dos alunos ingressantes e dos advindos de camadas antes alijadas do ensino superior. Relata experiências institucionais positivas para o sucesso escolar e coloca como desafio para a democratização do ensino superior a importância de se aliar a ampliação do acesso a políticas institucionais, que possibilitem a todos os acadêmicos condições propícias de inserção e desenvolvimento no ambiente universitário.

Palavras-chave: Expansão no ensino superior; Evasão no ensino superior; Permanência na educação superior

\begin{abstract}
This article reflects the role of institutional policies towards ensuring permanence and school performance in the context of widening access to higher education in Brazil. It considers the issue of evasion and difficulties, especially those groups who were historical excluded of higher education. It reports positive institutional experiences for success in school and puts a challenge to the democratization of higher education the importance of combining increased access to institutional policies that enable all academics favorable conditions for integration and development in the university environment.
\end{abstract}

Keywords: Higher education expansion; Retention in higher education; Educational policies in higher education

\section{Resumen}

El artículo refleja la importancia de las políticas institucionales dirigidas a garantizar la permanencia y rendimiento escolar en el contexto de incrementar el acceso a la educación superior en Brasil. Considera que la cuestión de la evasión y las dificultades encontradas, especialmente por los estudiantes iniciantes y procedentes de las capas antes empujadas a fuera de la educación superior. Cuenta de las experiencias institucionales positivas para el éxito escolar y plantea un desafío para la democratización de la educación superior que és de la importancia de combinar un mayor acceso a las políticas institucionales que permitan a todas las condiciones favorables académicos para la integración y el desarrollo en el ámbito universitario.

Palabras clave: Expansión de la educación superior; Deserción en la educación superior; Ppermanencia en la educación superior.

1 Este artigo é decorrência de reflexões iniciadas na Disciplina Docência Universitária e Complexidade: contextos, formação e práticas, ministrada pela Profa. Dra. Maria Isabel de Almeida.

2 Doutorando do Programa de pós-graduação da Faculdade de Educação da USP. Prof. da UNITAU e da Faculdade Dehoniana. E-mail: siluco@uol.com.br 3 Doutoranda do Programa de pós-graduação da Faculdade de Educação da USP. Analista Pedagógica Editora FTD. E-mail: sowdias@gmail.com 


\section{Introdução}

O ensino superior brasileiro registrou uma ampla expansão a partir da segunda metade dos anos noventa, acompanhando um processo de ampliação também registrado em outras partes do mundo. Diferentes estudos, como os de Ezcurra (2009), Almeida (2012) e Belettati (2011), apontam que esse crescimento tem se dado majoritariamente com o ingresso de alunos pertencentes a camadas de renda menos favorecidas da população, advindos da escola pública, que muitas vezes enfrentam grandes desafios para o bom desempenho e continuidade de seus estudos no nível superior. A inclusão desses novos sujeitos no ensino superior contou com estratégias como o Programa de Financiamento Estudantil (FIES) e o Programa Universidade para Todos (PROUNI), os quais têm sido fundamentais para a expansão e a consolidação da expansão do ensino superior privado. No setor público, ocorre uma ampliação das vagas, sobretudo nas Instituições Federais de Ensino Superior (IFES), e o desenvolvimento de políticas de ação afirmativa, na modalidade cotas, as quais objetivam o acesso das diferentes camadas sociais à universidade pública, com destaque para o aluno que cursou a sua formação básica na escola pública.

Entre as dificuldades desses alunos estão a necessidade de se conciliar trabalho e estudo, a adaptação a um novo sistema de ensino, o que exige maior autonomia, conhecimentos prévios formais e informais de maior complexidade, aprendizados nem sempre vivenciados pelos alunos de camadas mais populares. Sem contar os desafios advindos de uma situação financeira muitas vezes desfavorável, o que implica em dificuldades para compra de livros, deslocamento para congressos e eventos e atividades extraclasse.

Nesse contexto de crescimento significativo de matrículas de estudantes de camadas menos privilegiadas, é preciso considerar o quanto as condições encontradas por esses alunos nas instituições de ensino superior favorece a permanência. Em análise feita a partir dos dados do Censo da Educação Superior, Silva afirma que "até 2008, isto é, que a Evasão Anual do Ensino Superior Brasileiro se mantinha próxima a 20\%, na última década parece ser confirmado pelos cálculos atuais, que a situam, mais precisamente, entre 17,14\% e 18,69\%" (Silva Filho e Lobo, 2012).

Dessa forma, é preciso considerar que os dados sobre evasão mostram que este é um fenômeno frequente, com pouca alteração em termos percentuais, mas que, diante de um panorama de crescimento de matrículas, esses números passam a ser relacionados a um número muito mais significativo de estudantes e, portanto, um fenômeno que merece análise e enfrentamento, para que se realize, de fato, uma maior democratização do Ensino Superior (ES).

A busca para se realizar a meta estabelecida no Plano Nacional de Educação (PNE) de que um terço da população na faixa etária de 18 a 24 anos tenha ou concluído o ES ou nele tenha ingressado até 2020, coloca em relevância a necessidade de se construir estratégias que possam garantir uma maior permanência e bom desempenho escolar.

Com isso, o presente texto apresenta dados recentes sobre a expansão do ensino superior, considera o fenômeno da evasão e procura refletir a respeito do papel das Instituições de Ensino Superior (IES) no desenvolvimento de estruturas de apoio capazes de garantir melhorias no sucesso escolar a partir do suporte social, material e pedagógico. Nessa direção, os autores relatam duas experiências positivas de apoios institucionais, uma vivenciada como discente em uma universidade norte-americana, outra como docente em uma faculdade filantrópica do interior do Estado de São Paulo, com o objetivo de evidenciar a reflexão a respeito de fatores significativos que podem contribuir para a permanência e sucesso escolar dos alunos recém-ingressantes no ES, principalmente os que carregam maiores dificuldades para sua permanência neste nível de ensino. 


\section{Expansão do ensino superior no Brasil: o desafio da permanência}

A dimensão da ampliação do ES no Brasil pode ser auferida com destaque no aumento do número de matrículas na primeira década deste século. De acordo com os dados do Censo da Educação Superior, no ano de 2013 registrou-se um total de 7.305.977 matrículas, o que representa um crescimento de quase $100 \% \mathrm{em}$ uma década, considerando o total de matrículas em 2003, de 3.887.022. Esta expansão pode ser observada tanto no setor público quanto no setor privado. Porém, o maior incremento se deu entre as instituições privadas, as quais respondem por cerca de $74 \%$ das matrículas.

Tabela 1- Evolução do número de matrícula, ingressos e concluintes em cursos de graduação presenciais e à distância (1995 - 2012)

\begin{tabular}{|c|c|c|c|c|c|c|c|}
\hline Ano & 1995 & 2003 & 2009 & 2010 & 2011 & 2012 & 2013 \\
\hline Matrícula & 1.759 .703 & 3.887 .022 & 5.954 .021 & 6.379 .299 & 6.739 .689 & 7.037 .688 & 7.305 .977 \\
\hline Ingressos & 510.377 & 1.262 .954 & 2.065 .082 & 2.182 .229 & 2.346 .695 & 2.747 .089 & 2.742 .950 \\
\hline Concluintes & 254.401 & 528.223 & 959.197 & 973.839 & 1.016 .713 & 1.050 .413 & 991.010 \\
\hline
\end{tabular}

Fonte: Sinopse da educação superior - INEP.

Os dados da Tabela 1 permitem observar a significativa ampliação do acesso, com o ingresso de camadas sociais mais populares no ensino superior. Considerando a evolução do número de ingressantes, pode-se observar um movimento ascendente nos percentuais de crescimento: de 2009 para 2010, 5,67\%, de 2010 para 2011, 7,53\% e de 2011 para 2012 17,06\%. Os dados de 2013 apresentam uma ligeira queda neste movimento ascendente, apresentando um crescimento de 16,8\%. Esta pequena desaceleração no ritmo de crescimento também se observa nos dados da matrícula e nos de concluintes. Vale ressaltar ainda que, no ano de 2012, ocorre um salto no percentual de crescimento de ingressantes; porém, o mesmo não acontece com o crescimento de matrículas, que foi de 4,42\%. Esta desproporção entre o aumento dos ingressantes e do número de matrículas também não é decorrência de um aumento maior no número de concluintes, pois este foi de 3,31\%. Esta comparação entre os dados de ingressantes, matrículas e concluintes entre 2011 e 2012 deixa transparecer o fato de que um número expressivo de estudantes - por diferentes motivos que carecem de análise cuidadosa não concluem seu curso superior.

Não obstante os avanços das pesquisas sobre ES, a evasão ainda é um aspecto pouco explorado tanto no ensino público como no ensino privado. Pode-se dizer que a questão da evasão educacional está relacionada a múltiplos fatores, como características pessoais, condições econômicas, dúvidas em relação à opção realizada, entre outras. Como afirmam Baggi e Lopes (2011), a evasão escolar é um fenômeno complexo, que pode ser definido como a interrupção no ciclo de estudos e que pode ser provocada por inúmeros fatores: pessoais, familiares, sociais, econômicos ou institucionais.

Para Mohelecke (2007), a maior parte dos estudos sobre evasão escolar tem como foco o ensino básico, enquanto no ES o tema ainda é pouco explorado, sendo necessário o desenvolvimento de modelos teóricos que ajudem a explicar as causas da evasão. Segundo a autora, os fatores da evasão podem ser elencados em individuais e institucionais:

Entre os fatores individuais da evasão constam: a incerteza quanto ao curso, própria de um processo de busca do indivíduo que em geral tem de escolher sua área de formação ainda muito jovem; motivos familiares como doença, necessidade de ajuda financeira, nascimento de criança, compromissos maritais; a necessidade de trabalhar. Os fatores institucionais mais frequentes são: desilusão com o curso; problemas relacionados ao curso como currículo (muito rígido, inadequado para o aluno trabalhador), ao relacionamento com professores, com colegas, funcionários; dificuldade de acesso à instituição (MOEHLECKE, 2007, p. 13). 
O fenômeno da evasão envolve uma articulação entre múltiplos fatores, ou seja, as dificuldades individuais podem ser mais bem superadas na presença de um bom suporte institucional, do mesmo modo que as limitações institucionais prejudicam sobremaneira os que carregam as maiores dificuldades.

Estudo realizado por Silva Filho et al (2007), a partir de dados do INEP, demonstra que no período de 2000 e 2005, a evasão média para o conjunto de IES no Brasil foi de 22\%. Se considerarmos apenas as instituições públicas, esse número é menor, chega a 12\%, enquanto nas universidades particulares chega a 26\%. Esses dados apontam que o tema da evasão tem uma incidência maior nas IES particulares, onde os fatores econômicos podem ter maior relevância. Silva Filho et al (2007) comentam algumas consequências da evasão:

A evasão estudantil no ensino superior é um problema internacional que afeta o resultado dos sistemas educacionais. As perdas de estudantes que iniciam, mas não terminam seus cursos são desperdícios sociais, acadêmicos econômicos. No setor público, são recursos públicos investidos sem o devido retorno. No setor privado, é uma importante perda de receitas. Em ambos os casos, a evasão é uma fonte de ociosidade de professores, funcionários, equipamentos e espaço físico (p. 642).

Para além destes aspectos de natureza quantitativa, a questão da evasão precisa ser considerada em uma dimensão qualitativa, desde a questão do indivíduo que tem a sua autoestima resvalada por um fracasso, até a questão política de democratização do ES. A ampliação das oportunidades de acesso sem o contraponto de apoios para se garantir a permanência reforça a permanência das desigualdades, como apontado nos estudos de Dubet (2012).

Para o sociólogo francês, as políticas de enfrentamento de desigualdades históricas precisariam articular uma combinação de iniciativas, que incluiriam a promoção da igualdade de posições com a igualdade de oportunidades. Para o autor, esses dois conceitos, apesar de semelhantes, guardam diferenças que devem ser analisadas com cuidado. No caso da igualdade de posições, o foco está na estrutura social a partir dos lugares ocupados pelos indivíduos na sociedade, de forma a abranger todos os indivíduos, minorias e maiorias, envolvendo todas as faixas etárias. Dessa forma, uma política focada na igualdade de posições procura reduzir as desigualdades de renda, de condições de vida, de acesso a serviços. Em suma, procura reduzir a distância entre essas posições sociais e, com isso, seria possível estimular a mobilidade social a partir de uma distribuição de renda e condições sociais melhores para todos os cidadãos. Assim, a igualdade de posições pressupõe um Estado de Bem Estar Social consolidado.

Por outro lado, a igualdade de oportunidades baseia-se no princípio meritocrático, que não tem como objetivo reduzir as desigualdades das posições sociais, mas lutar contra as discriminações que constituem obstáculos à realização do mérito, permitindo a cada um ter acesso a posições desiguais ao final de uma competição equitativa, na qual indivíduos iguais se enfrentam para ocupar lugares sociais hierarquizados. Dessa forma, as diferenças de gênero, grupo étnico ou racial, condição social são mantidas, ampliando-se as possibilidades de acesso ou concorrência para determinadas posições, como no caso das cotas para ingresso nas universidades públicas.

As políticas de ação afirmativa estão relacionadas à promoção da igualdade de oportunidade, pois têm como objetivo oferecer a possiblidade de concorrer a determinadas vagas no ES a indivíduos que não teriam esse acesso. Mas, como Dubet chama a atenção, essas medidas não atuam na causa do problema e podem não ter a eficácia necessária, pois são baseadas no mérito: apenas os alunos mais bem classificados em sua categoria (negros, indígenas, deficientes, oriundos de escola pública) têm acesso a essas vagas. Com isso, mantém-se a meritocracia e pode-se não alcançar a diminuição das desigualdades, uma vez que alunos que estejam nessas categorias podem nem se inscreverem nas universidades por considerarem que não seriam bons o suficiente e, uma vez matriculados, podem apresentar maiores dificuldades de permanência (DUBET, 2004, p. 541).

Nessa direção, os estudos de Belletati (2011), Ezcurra (2009), Tarábola (2010) e Zago (2006) também afirmam que alunos advindos de classes sociais vulneráveis têm uma tendência a apresentar diferentes problemas de adaptação ao ambiente acadêmico e, por isso, estariam mais sujeitos a terem dificuldade para concluir o 
curso universitário. Ezcurra (2011), ao tratar da massificação do ensino superior, relata que entre os desafios enfrentados por esses grupos das camadas desfavorecidas da sociedade na realização da graduação superior está uma preparação acadêmica marcada por um "capital cultural insuficiente en el punto de partida". (p. 65)

Para a autora, esse capital cultural não se refere a apenas certas habilidades cognitivas, mas envolve alguns hábitos que facilitam a vida acadêmica, como ter metodologia para ler e estudar. Além disso, engloba outros fatores como as expectativas sobre o próprio desempenho, o compromisso ou o engajamento estudantil, a quantidade e a qualidade do tempo que dedicam para o estudo e outras atividades acadêmicas. Outro aspecto importante é que esses alunos se constituem na primeira geração de acadêmicos de suas famílias e tendem a apresentar um comportamento de pouca confiança em si mesmos, baixa expectativa sobre seu desempenho e, principalmente, um grande medo do fracasso (p. 65).

Essa dada condição cultural é diferente daquilo que se espera no habitus academicus dominante. Por parte dos professores, pesa um olhar sobre os alunos: de que estes não são tão bem preparados como eram os alunos no passado. Por parte das instituições, pesa um olhar, sobretudo, "en la enseñanza, y en particular en las aulas, en las experiências académicas cotidianas" (EZCURRA, 2011, p. 66). Desse modo, tende-se a excluir os alunos sem o capital cultural desejado, empurrando-os para o fracasso acadêmico. Essa mesma lógica também é denunciada por Dubet (2011): "durante muito tempo o fracasso dos alunos não foi considerado responsabilidade da escola" (p. 297).

Ainda segundo Ezcurra (2011) esse contexto contribui para que muitos estudantes não consigam concluir sua graduação, uma vez que os índices de evasão nessa "franja social" são elevados. A partir de estudos realizados sobre a massificação do ensino superior nos Estados Unidos e na América Latina, a autora afirma "que los avances en la graduación involucraron a una parte exigua de los estudiantes de menores recursos, mientras que beneficiaron casi exclusivamente a los de estratos medios y altos". Considerando os índices mais elevados de evasão entre os mais desfavorecidos, Ezcurra afirma que a "la presunta puerta abierta a la educación superior para aquellos estratos no es tal, sino que se trata de una puerta giratória" (p. 62). Ou seja, o ingresso no ensino superior para muitos estudantes de camadas sociais mais baixas pode se transformar em uma porta giratória tanto no sentido de que nem todos a atravessam, mas também, no sentido de que dadas as condições precárias de alguns cursos e seus diplomas desvalorizados, muitos vão mudando sem saírem do lugar, com os investimentos em um curso superior não significando a possibilidade de uma transformação mais profunda nas condições de existência.

Nessa direção, Zago (2006), ao refletir sobre o percurso de estudantes universitários de camadas populares, traz relatos dos custos pessoais de se estudar em condições adversas: dificuldade de cumprir com as obrigações acadêmicas, não participação em atividades fora do horário das aulas, não participação nas atividades sociais da turma, sobretudo quando se inserem em cursos mais elitistas.

Se o ingresso no ensino superior representa para esse grupo de estudantes 'uma vitória', a outra será certamente garantir sua permanência até a finalização do curso. Originários de famílias de baixa renda, esses estudantes precisam financiar seus estudos e, em alguns casos, contam com uma pequena ajuda familiar para essa finalidade. Provenientes de outras cidades ou estados, pouco mais da metade tem suas despesas acrescidas pelo fato de não morar com a família. Nesses casos, residem na casa do estudante universitário (quando há vaga), ou com parente, ou ainda, dividem casa ou apartamento com colegas (ZAG0, 2006, p. 233).

Ainda ressaltando as dificuldades das camadas desfavorecidas da sociedade, Pacheco e Ristoff (2004) chamam a atenção para um estudo do Observatório Universitário da Universidade Cândido Mendes, o qual revela que $25 \%$ dos potenciais alunos universitários são tão carentes que "não têm condições de entrar no ensino superior, mesmo se ele for gratuito" (p. 9). Este dado aponta para a necessidade de políticas institucionais que sejam dirigidas a promover a permanência dos estudantes nos cursos universitários, principalmente daqueles com maiores dificuldades. 


\section{O papel da universidade no favorecimento da permanência no ensino superior}

Entre os fatores elencados para a evasão/permanência, costuma se sobressair a questão econômica. Porém, em entrevista à Revista Ensino Superior (outubro/2013, p.31), a diretora acadêmica da Faculdade Santa Marcelina, Sueli de Moura, afirma que nem sempre esse é o principal motivo: "nas pesquisas internas, o item 'não tenho condições financeiras' aparece em primeiro lugar, mas quando o aluno realmente gosta do curso e quer ser um profissional da área, consegue recursos". Mais do que discutir a relevância do aspecto econômico, esta fala sinaliza sobre a importância de se considerar outros fatores, no sentido de que o aluno pode perceber que o curso é um bom investimento. Por exemplo, se ancorado em uma boa estrutura de apoio, o aluno tende a ter condições de buscar alternativas para resolver a situação econômica.

Dada a multiplicidade de fatores relacionados à evasão e o desafio de garantir a permanência dos novos sujeitos no espaço acadêmico e com ensino de qualidade, têm crescido os esforços das IES por políticas institucionais que promovam a permanência dos alunos.

Vale destacar que as IES têm papel importante em relação à permanência dos alunos quando considerados a infraestrutura ofertada, como moradia estudantil, apoio ao transporte, biblioteca, refeitório, apoio para estudantes com deficiência física, entre outros. Para autores como Tinto, a permanência do estudante no ensino superior é bastante influenciada pela integração ao ambiente social e acadêmico, além de estar associada ao nível de expectativas do aluno. Dessa forma, quanto maiores forem as expectativas (educacionais e de carreira) e quanto mais satisfatória for sua integração social e acadêmica, suas chances de evasão diminuem. Nas palavras de Tinto (1993): "Quanto maior o comprometimento do aluno com a instituição e com os seus próprios objetivos, e elevado for o nível de integração acadêmica e social desse aluno, menor a probabilidade de evasão" (TINTO, 1993:130).

Nesse sentido, uma parte importante dessa problemática relaciona-se aos alunos recém-ingressantes, ou seja, os programas de acolhida e acompanhamento aos alunos do primeiro ano do ensino superior. Como aponta Ezcurra, o primeiro ano do ES trata-se de um período de transição e ajuste ao mundo universitário novo, com experiências que costumam ser difíceis, considerando o caráter de adaptação e a inexperiência dos alunos em relação ao que esperar do ambiente acadêmico (EZCURRA, 2009).

Para responder a essa demanda, desenvolve-se nos Estados Unidos, desde os anos oitenta, um movimento que procura, por meio de diferentes iniciativas, acolher de forma diferenciada e abrangente os alunos ingressantes. Registre-se ainda que estes programas não se destinam apenas a alunos de baixa renda ou de minorias étnicas, mas buscam atender a todos os estudantes.

Esse é o caso da Vanderbilt University, instituição de ES privada, localizada na cidade de Nashville, no Estado do Tennessee, no sudeste dos Estados Unidos, fundada em 1873. A universidade possui um programa chamado Experiência do Primeiro Ano (The First-Year Experience), que consiste em que todos os alunos do primeiro ano morem no campus da universidade, inspirado no modelo utilizado na Inglaterra pelas Universidades de Oxford e Cambridge.

A proposta foi criada em 2008 e tem como objetivo estimular a interação e a aprendizagem conjunta entre os estudantes, professores e tutores. Os alunos ingressantes devem morar obrigatoriamente na universidade durante o primeiro ano e a mudança para o campus é feita com um grande ritual que envolve professores, alunos voluntários e funcionários. Os alunos moram em um conjunto residencial composto por dez prédios, sendo que em cada um deles mora um professor coordenador da casa e um mentor, com suas respectivas famílias, que são os responsáveis por organizar as atividades da casa, orientar e ajudar os estudantes em caso de problemas. Além disso, o reitor de graduação mora com sua família em uma casa próxima ao complexo dos estudantes.

O complexo de prédios possui uma área comum, com refeitório, sala de ginástica, correios, suporte para uso de computador e apoio para produção de texto, que também podem ser utilizados por todos os alunos da 
universidade. A universidade disponibiliza auxílio de tutores, grupos de estudos, oficinas para o desenvolvimento de habilidades de estudos e de pensamento crítico. São oferecidos ainda apartamentos adaptados para aqueles que possuem deficiência visual, de mobilidade ou surdez, além do auxílio de intérpretes para linguagem libras, audiolivros, serviço de anotação em aula e leitura. Além de atendimento médico, orientação para estudantes internacionais, apoio psicológico e aconselhamento religioso e, no caso dos que necessitam de apoio financeiro, são disponibilizadas bolsas de estudos. A universidade considera que graças ao conjunto dessas ações seus dados de evasão no $1^{\circ}$ ano são bem baixos, chegando a índices de permanência na universidade de $97 \%$.

O relato acima apresenta um conjunto de ações voltadas para o aluno ingressante no sentido de possibilitar uma boa interação do aluno com o ambiente acadêmico em seu conjunto. Ele, obrigatoriamente, mora na Universidade, estabelecendo relações de proximidade com colegas e professores, a começar com um ritual de acolhida, que acompanha o aluno ingressante desde a mudança para o campus. Ainda mais, conta com toda uma rede de apoio que atende às questões de sobrevivência e oferecem suporte para um bom ambiente de estudos. O resultado é a pequena taxa de desistência escolar, em torno de 3\% no primeiro ano.

Se a experiência acima consiste em uma política da IES, o relato abaixo decorre de uma experiência de trabalho em uma faculdade filantrópica, na qual parte dos alunos são vocacionados e contam com uma estrutura de apoio para além do ambiente da IES, ou seja, residem em Casas de Formação, também chamadas de Seminário, Convento, Comunidades. Trata-se da Faculdade Dehoniana, localizada no município de Taubaté, no interior do Estado de São Paulo, região do Vale do Paraíba, que oferece os cursos de Filosofia e Teologia, os quais são exigências para a formação sacerdotal. Além dos seminaristas, os cursos contam também com uma participação de alunos da comunidade em geral.

As casas de formação garantem as questões básicas, como moradia e alimentação e constituem um ambiente que valoriza a vida estudantil; oferecem uma estrutura que facilita os estudos, como biblioteca, acesso a computadores e internet, salas de estudo individual e em grupo. Os cursos são matutinos e, no restante do tempo, além de compromissos com a comunidade, há os horários livres para a dedicação aos estudos. Destaca-se, sobretudo para os alunos ingressantes, a possibilidade de morar na mesma casa com colegas veteranos, podendo partilhar cotidianamente informações sobre o curso, como professores, autores, textos, trabalhos de conclusão de curso. Contam ainda com a presença de um responsável geral pela formação, que pode acompanhar as dificuldades e buscar outros apoios profissionais, como o suporte de um psicólogo ou de um professor de língua portuguesa.

Estes alunos vocacionados compõem um grupo bastante diversificado, tendo dentre eles alguns com significativa distorção série/idade e uma formação precária na educação básica. Observa-se que esses estudantes conseguem ter, ao longo do curso, uma superação das dificuldades e um bom resultado acadêmico, apresentando, por exemplo, no caso do curso de Filosofia, boas monografias como trabalho de conclusão de curso. Os casos de evasão se dão mais por um redirecionamento na opção vocacional do que por dificuldades nos estudos. Também no caso do curso de filosofia, ressalta-se ainda a conquista de uma nota 4,0 no último exame do Enade.

Para analisar esse resultado, é preciso considerar também a infraestrutura existente na instituição, como biblioteca ampla e com um bom acervo, sala de informática e salas de aula bem aparelhadas. Na parte acadêmica, a maioria dos professores são mestres ou doutores e as turmas são relativamente pequenas, facilitando um melhor acompanhamento dos alunos pelos professores.

A experiência da Faculdade Dehoniana apresenta características de uma estrutura favorável ao desenvolvimento acadêmico, demonstrando o quanto são significativos aspectos como ter um tempo para se dedicar aos estudos, um ambiente que estimula a educação, a integração entre alunos ingressantes e veteranos, além de uma estrutura que garanta questões básicas, como moradia, alimentação e saúde. Deve-se considerar ainda o engajamento dos alunos na própria formação, em decorrência da própria vocação religiosa de muitos, no sentido de uma preparação para uma vida de serviço à comunidade. 
É preciso levar em conta que estas experiências relatadas acima estão distantes da maior parte da realidade do ES no Brasil. Porém, considerá-las ajuda a vislumbrar a necessidade de um trabalho diferenciado na acolhida dos alunos ao ambiente universitário. Desse modo, podemos sistematizar o significado destas experiências para o sucesso escolar destacando três aspectos. Primeiramente, permitem aos graduandos uma tranquilidade em relação a questões básicas da sobrevivência, como moradia e alimentação. Em segundo lugar, possibilitam um ambiente favorável com lugar e horário para os estudos, acesso a biblioteca e sala de informática e, sobretudo, um ambiente de socialização acadêmica, marcado pela convivência com colegas e responsáveis pela formação. Por fim, ressaltam-se as condições institucionais que garantem a qualidade acadêmica, como uma boa infraestrutura, salas de aula com número adequado de alunos, possibilitando uma proximidade com os professores.

Estes aspectos apontam que o desempenho escolar é decorrência de um conjunto de fatores e que a educação é uma atividade que envolve pessoas e instituições. Como afirma Rué (2007):

son las concepciones culturales de cada grupo humano, las condiciones organizativas de esta actividad, los rasgos personales de los receptores de la misma, las representaciones mutuas de los que interactúan y sus respectivas lo que, en un momento y en contexto determinados, proporciona a dicha actividad de le ensenar y de aprender como una actividad social y organizativamente construida (p. 141).

Nesse sentido, ao se analisar as condições favoráveis de permanência e bom desempenho escolar, sobretudo daqueles que carregam maiores carências, também é preciso atentar para o papel dos professores tanto para o aprendizado dos alunos como, também, na motivação para superar dificuldades, priorizar a formação e poder avançar com qualidade nos estudos.

Apesar de sua importância, por diversas razões estes suporte e incentivo por parte dos professores nem sempre estão presentes. Milner (2010) chama a atenção para o fato de que muitos educadores tendem a não reconhecer certas habilidades que estudantes de grupos economicamente desfavorecidos possuem e a apenas visualizar nesses alunos suas deficiências, o que "contribui para a criação de um círculo vicioso: educadores não ensinam com rigor e altas expectativas, estudantes não aprendem, estudantes vão mal nas avaliações e todos os envolvidos se perguntam o porquê" (p.36).

Nesse contexto de desqualificação dos alunos, sobretudo dos que advém das camadas mais desfavorecidas socialmente, as políticas de ampliação do acesso e até mesmo a construção de estruturas de apoio terão efeito limitado no processo de democratização do ensino superior. Como ressalta Ezcurra (2009, p. 112), o que mais garante a permanência é uma boa educação e a aula constitui um momento decisivo, sobretudo para os alunos que trabalham e têm pouco tempo para os estudos, tornando-se "quase o único lugar onde se encontram com seus pares e com os docentes". Para tanto, ressalta-se a importância de uma expectativa positiva dos professores quanto aos alunos, expressa em uma relação que permita ao aluno ganhar autoconfiança em relação às suas capacidades e mais à vontade para pedir ajuda quando necessário.

\section{Considerações finais}

No contexto da expansão do ES, o presente texto procurou refletir sobre o papel que as IES podem oferecer em termos de estruturas de apoio para os alunos, principalmente para os recém-ingressantes. O que a universidade faz para atender aos acadêmicos ingressantes econômica e socialmente desfavorecidos? Ou que programas dão conta da inserção universitária, cuidando da transição da cultura escolar da educação básica para o hábitus academicus? Na busca de construir respostas a estas questões, relataram-se duas experiências, uma em universidade americana e outra em uma faculdade filantrópica que, apesar de serem parte de duas realidades bastante diferentes da maioria das IES brasileiras, podem ser consideradas experiências positivas da existência de um conjunto de ações institucionais, que denominamos estruturas de apoio, as quais estimulam o desempenho e a permanência dos alunos no ensino superior. 
Essas estruturas de apoio, formadas basicamente pela oferta de moradia e condições para que o aluno possa diminuir seus deslocamentos, ter mais tempo para se dedicar aos estudos, além de suporte para aulas e tutoria, apresentam-se como um diferencial positivo que deveria ser oferecido não apenas para os ingressantes e alunos desfavorecidos, mas a todos que tenham necessidade. Além disso, essa rede de suporte também estimula a interação entre os estudantes e professores, de forma que os alunos ingressantes se sentem acolhidos em um grupo e estimulados a dele participar.

Ao mesmo tempo, é preciso destacar o papel do professor, seu relacionamento com os alunos, expectativas em relação à sua aprendizagem, metodologia de ensino e seu preparo para a docência têm papel importante na relação do aluno com a universidade. Nesse sentido, torna-se fundamental que a formação de professores para o ES considere e valorize a reflexão sobre os diferentes perfis dos sujeitos que compõem a sala de aula.

A ampliação do acesso ao nível superior no Brasil pode ser considerada uma grande conquista social. Atualmente, camadas antes alijadas desta possibilidade têm acesso ao primeiro diploma de curso superior de sua geração. Encontra-se em transformação a realidade de um ES marcado pelo prestígio, reservado a camadas privilegiadas e, portanto, criteriosamente selecionadas. Porém, para que se possam saldar dívidas históricas e avançar no processo de democratização do ES, é preciso desfazer crenças e preconceitos segundo os quais a universidade é para poucos e que aqueles que estão ingressando agora não têm condições de acompanhar as aulas ou ter uma formação de qualidade. É preciso que as IES possam formar adequadamente a todos os alunos, independentemente de classe social, formação cultural, sobretudo os advindos de camadas economicamente desfavorecidas e/ou pertencentes a grupos historicamente excluídos desse nível de ensino, como negros e indígenas.

Não basta ampliar a oferta de oportunidades de acesso, focada no critério da meritocracia, pois, como afirma Dubet (2004), nesse modelo "quanto mais favorecido o meio do qual o aluno se origina, maior a probabilidade de ser um bom aluno, quanto mais ele for um bom aluno, maior será sua possibilidade de aceder a uma educação melhor, mais diplomas ele obterá e mais ele será favorecido" (p. 543). Sem falar que nesse modelo, os alunos que não conseguem avançar no ensino, ou seja, aqueles com baixo desempenho, que não conseguem acompanhar as aulas ou que acabam desistindo de estudar, sejam considerados os únicos responsáveis por seus "fracassos" e não vítimas de um sistema injusto que não lhes permitiu ter as mesmas chances de sucesso que os outros.

Desse modo, para se considerar a expressiva ampliação no número de vagas no ES como um panorama de enfrentamento das desigualdades educacionais, é preciso certificar de que forma os estudantes, principalmente de baixa renda, estão sendo acolhidos. Para que exista a real possibilidade de mobilidade social, é preciso condições a fim de que esses alunos não apenas ingressem, mas permaneçam e tenham uma boa formação universitária.

Mas o desafio é grande. Uma maior alternativa de acesso já se consolida para setores mais amplos da população e uma maior atenção para as condições de permanência se impõe como necessidade. Por parte das IES particulares, os altos investimentos em captação de alunos requerem a contrapartida de investimentos para uma maior permanência, pois certamente será um bom investimento a redução dos índices de evasão. Por parte das IES públicas, segue o desafio de ampliar as condições de acesso, acompanhado de estruturas de apoio que garantam a permanência e possibilitem a superação das carências da formação básica.

Como o tema é recente e bastante complexo, é preciso ainda ser mais bem explorado por meio de pesquisas, no sentido de ampliar os dados e perspectivas tanto do ponto de vista da construção ou aperfeiçoamento de estruturas de apoio como da melhoria da qualidade de ensino, tratando das necessidades pedagógicas decorrentes dos novos sujeitos e da importância da formação pedagógica do professor do ensino superior. 


\section{Referências}

ALMEIDA, M. I. Formação do Professor do Ensino Superior, desafios e políticas institucionais,São Paulo, Cortez, 2012.

BAGGI, C. A. S.; LOPES, D. A. L.. Evasão e avaliação institucional no ensino superior: uma discussão bibliográfica. Avaliação, Campinas; Sorocaba, SP, v. 16, n. 2, p. 355-374, jul. 2011.

BAIN, K. Lo que hacen los mejores professores universitários. Barcelona, Univ. De Valencia, 2007.

BELETTATI. Dificuldades de alunos ingressantes na universidade pública: indicadores para reflexões sobre a docência universitária, Tese, orientador: Maria Isabel de Almeida, Faculdade de Educação, Universidade de São Paulo, 2011.

BIGGS, J. Cambiar la enseñanza universitária. In: Calidad del Aprendizaje universitária.Madrid: Narcea, 2006, p. 19-53.

BRASIL, MEC/INEP. Sinopse do ensino superior 1995, 2003, 2009 - 2013. Disponível em: http://portal.inep. gov.br/superior-censosuperior-sinopse

DUBET, F. O que é uma escola justa? Cadernos de Pesquisa, v. 34, n. 123, set./dez. 2004. Mutações cruzadas: a cidadania e a escola. Revista Brasileira de Educação v. 16 n. 47 maio-ago. 2011 Os limites da igualdade de oportunidade. Cadernos Cenpec, São Paulo, 2012, v.2, n.2, p.171-179, dez. 2012.

EZCURRA, A. M. Os estudantes recém-ingressados: democratização e responsabilidades das instituições universitárias. In: PIMENTA \& ALMEIDA (Orgs). Pedagogia Universitária. São Paulo, EDUSP, (2009).

Masificación y ensenãnza superior: uma inclusión excluyente. Algunas hipótesis y conceptos clave. En: LAMARRA, Norberto Fernandez y Paula, Maria de Fátima Costa (Compiladores). La democratización de La educación superior em América Latina. Argentina: EDUNTREF, 2011.

MILNER, R. Start Where you are but don't stay there. Understanding Diversity, Opportunity Gaps, and Teaching in Today's Classrooms, Harvard Education Press, (2010).

MOEHLECKE, S. Avaliação institucional no ensino superior: como acompanhar a trajetória dos estudantes de graduação? UFRJ. (2007), disponível em: http://www.anpae.org.br/congressos_antigos/simposio2007/401. pdf, acessado em 05/12/2013.

PACHECO, E.; RISTOFF, D. I. Educação superior: democratizando o acesso. Brasília: Instituto Nacional de Estudos e Pesquisas Educacionais, 2004 (Série Documental. Textos para discussão n. 12).

RUÉ, J. Concretar la relación entre enseñanza y aprendizaje + Planificar y organizar cada matéria: elaborar La guia de La asignatura. In: Enseñar en La universidad. Madrid, Narcea, 2007, p. 141-188.

SILVA FILHO, R. L. L. et al. A evasão no ensino superior brasileiro. Cadernos de Pesquisa, v. 37, n. 132, set641-659, set./dez 2007.

SILVA FILHO, R. L. L.; LOBO, M. B. C. Como a mudança na metodologia do Inep altera o cálculo da evasão, 2012, disponível em:

http://www.institutolobo.org.br/imagens/pdf/artigos/art_079.pdf, acessado em 31/08/2014

TARÁBOLA, F. Quando o ornitorrinco vai à universidade: longevidade e sucesso escolares de jovens oriundos de escolas públicas na USP., Orientador: Teresa Cristina R. Rego. (2010).

TINTO, V. Leaving college: rethinking the causes and cures of student attrition. 2. ed. Chicago: The University of Chicago, 1993. $312 \mathrm{p}$

ZAGO, N. Do acesso à permanência no ensino superior: percursos de estudantes universitários de camadas populares. Revista Brasileira de Educação, 2006, v. 11, n. 32, pp. 226 - 237. Disponível em: http:// www.scielo.br/pdf/rbedu/v11n32/a03v11n32.pdf

Recebido em Novembro de 2014 | Aprovado em Fevereiro de 2015 